\title{
Analysis and comparison of protein secondary structures in the rachis of avian flight feathers
}

\author{
Pin-Yen Lin ${ }^{1}$, Pei-Yu Huang ${ }^{2}$, Yao-Chang Lee ${ }^{\text {Corresp., } 2,3}$, Chen Siang Ng ${ }^{\text {Corresp. 1, 4, 5, } 6}$ \\ 1 Institute of Molecular and Cellular Biology, National Tsing Hua University, Hsinchu, Hsinchu, Taiwan \\ 2 National Synchrotron Radiation Research Center, Hsinchu, Hsinchu, Taiwan \\ 3 Department of Optics and Photonics, National Central University, Chung-Li, Taoyuan, Taiwan \\ 4 Department of Life Science, National Tsing Hua University, Hsinchu, Hsinhu, Taiwan \\ ${ }^{5}$ National Tsing Hua University, Bioresource Conservation Research Center, Hsinchu, Hsinchu, Taiwan \\ 6 The iEGG and Animal Biotechnology Center, National Chung Hsing University, Taichung, Taichung, Taiwan \\ Corresponding Authors: Yao-Chang Lee, Chen Siang Ng \\ Email address: yclee@nsrrc.org.tw, gcsng@life.nthu.edu.tw
}

Avians have evolved many different modes of flying as well as various types of feathers for adapting to varied environments. However, the protein content and ratio of protein secondary structures (PSSs) in mature flight feathers are less understood. Further research is needed to understand the proportions of PSSs in feather shafts adapted to various flight modes in different avian species. Flight feathers were analyzed in chicken, mallard, sacred ibis, crested goshawk, collared scops owl, budgie, and zebra finch to investigate the PSSs that have evolved in the feather cortex and medulla by using nondestructive attenuated total reflection Fourier transform infrared spectroscopy (ATR-FTIR). In addition, synchrotron radiation-based, Fourier transform infrared microspectroscopy (SR-FTIRM) was utilized to measure and analyze cross-sections of the feather shafts of seven bird species at a high lateral resolution to resolve the composition of proteins distributed within the sampled area of interest. In this study, significant amounts of $\alpha$-keratin and collagen components were observed in flight feather shafts, suggesting that these proteins play significant roles in the mechanical strength of flight feathers. This investigation increases our understanding of adaptations to flight by elucidating the structural and mechanistic basis of the feather composition. 


\section{Analysis and comparison of protein secondary} 3 structures in the rachis of avian flight feathers

${ }^{1}$ Institute of Molecular and Cellular Biology, National Tsing Hua University, Hsinchu 30013, Taiwan.

${ }^{2}$ National Synchrotron Radiation Research Center, Hsinchu 30076, Taiwan. Taiwan.

${ }^{6}$ The iEGG and Animal Biotechnology Center, National Chung Hsing University, Taichung, Taiwan.

Corresponding Author:

19 Yao-Chang Lee

National Synchrotron Radiation Research Center, Hsinchu 30076, Taiwan.

Email address: yclee@nsrrc.org.tw

\section{Chen Siang Ng}

Institute of Molecular and Cellular Biology, National Tsing Hua University, Hsinchu 30013, Taiwan.

Email address: gcsng@life.nthu.edu.tw

\section{Abstract}

Avians have evolved many different modes of flying as well as various types of feathers for adapting to varied environments. However, the protein content and ratio of protein secondary structures (PSSs) in mature flight feathers are less understood. Further research is needed to understand the proportions of PSSs in feather shafts adapted to various flight modes in different avian species. Flight feathers were analyzed in chicken, mallard, sacred ibis, crested goshawk, collared scops owl, budgie, and zebra finch to investigate the PSSs that have evolved in the feather cortex and medulla by using nondestructive attenuated total reflection Fourier transform infrared spectroscopy (ATR-FTIR). In addition, synchrotron radiation-based, Fourier transform infrared microspectroscopy (SR-FTIRM) was utilized to measure and analyze cross-sections of the feather shafts of seven bird species at a high lateral resolution to resolve the composition of proteins 
40

41

42

43

44

45

46

47

48

49

50

51

52

53

54

55

56

57

58

59

60

61

62

63

64

65

66

67

68

69

70

71

72

73

74

75

76

77

78

distributed within the sampled area of interest. In this study, significant amounts of $\alpha$-keratin and collagen components were observed in flight feather shafts, suggesting that these proteins play significant roles in the mechanical strength of flight feathers. This investigation increases our understanding of adaptations to flight by elucidating the structural and mechanistic basis of the feather composition.

\section{Introduction}

Feathers are rigid, complex structures in the epidermis of dinosaurs and birds (Chen, Foley et al. 2015, $\mathrm{Ng}$ and $\mathrm{Li}$ 2018). The earliest evidence of feathers has been suggested to derive from paleontological investigations of the fossils of Late Jurassic Theropod dinosaurs (Xu, Zhou et al. 2014). The feathers collected from different species of birds have many distinctions in shape, size, internal structure, and color; therefore, observing and comparing various feathers helps to further understand the characteristics of feathers among bird species and their functions.

The original function of feathers has been suggested not to be flight, as nonavian dinosaurs lacked the physical adaptations necessary for flying (Chuong, Wu et al. 2003). The mechanics of bird flight and energy consumption for this purpose are highly related to the intrastructure and morphology of feathers (Sullivan, Meyers et al. 2019). To satisfy the aerodynamic requirements of the function of avian flight, the component material and mechanical properties of flight feathers are critical (Lingham-Soliar 2014, Sullivan, Pissarenko et al. 2016, Sullivan, Wang et al. 2017).

The flight feathers of avians consist of a central shaft and vanes on both sides (Prum and Brush 2002, Chen, Foley et al. 2015), and the size of the inner vane is greater than that of the outer vane to reduce the resistance from aerodynamic forces (Feo, Field et al. 2015). The vanes are composed of barbs in a parallel arrangement, and numerous barbules are found on both sides of the barbs. The bow barbules have a dorsal spine, and the hook barbules have many hooklets, allowing adjacent barbs to be interlocked to form a complete vane (Zhang, Jiang et al. 2018), which can be separated into two parts by pulling the barbs apart and restored by gently stroking the feather (Kovalev, Filippov et al. 2014, Zhang, Jiang et al. 2018).

The shaft of flying feathers is divided into two parts: the rachis and calamus (Figure 1). Tough and lightweight feathers are composed of keratins and corneous proteins, and the fabric structure and multilayered arrangement of the cortex in the rachis confer it with good elasticity and resistance to fractures (Lingham-Soliar, Bonser et al. 2010, Laurent, Palmer et al. 2014, LinghamSoliar 2017). Although previous studies showed that the flexural stiffness of feathers could be mainly determined by the structure of the rachises rather than the material properties of keratins and corneous proteins (Bonser and Purslow 1995, Weiss, Schmitt et al. 2011, Bachmann, Emmerlich et al. 2012), the external morphology is not the single major factor determining rachis structural properties, but a combination of microstructural and material properties could be critical (Lees, Garner et al. 2017). In addition, the rachis has a less significant effect on the buckling stress and tensile strength of the rachis, which will affect the bending of the feathers to prevent the rachis 
79 from being cracked by external forces during flight (Wang and Meyers 2017, Zou, Zhou et al. 80 2019).

81 The laterally resolved distribution of $\alpha$ - and $\beta$-keratin in mature flight feathers can provide

82

83

84

85

86

87

88

89

90

91

92

93

94

95

96

97

98

99

100

101

102

103

104

105

106

107

108

109

110

111

112

113

114

115

116

117

two-dimensional information for understanding the mechanical requirements of the flight feathers to meet the aerodynamic needs of birds. This study also provides a novel perspective on the adaptation of the rachis medulla for flight. Various strategies and methods related to flight mechanics, such as gliding, hovering, bounding, flocking, and flapping, have been well investigated in different kinds of avians (Rayner 1982). The distribution pattern of the change in the mechanical force acting upon the wing is influenced by various flight modes. The loading of aerodynamic forces is applied mostly to the flight feather shaft; hence, the structural properties of rachises vary across the wingspan and among different birds (Ennos, Hickson et al. 1995, Pap, Osvath et al. 2015, Osvath, Vincze et al. 2020).

The number of corneous proteins invested in flight feathers and their structure varies with flying behavior and life history (Worcester 1996, Aparicio, Bonal et al. 2003, Lingham-Soliar, Bonser et al. 2010, Weber, Kranenbarg et al. 2010, Bachmann, Emmerlich et al. 2012, Wang, Nudds et al. 2012). The mechanism of keratin and corneous protein accumulation in the development of feathers needs to be further understood. The major components of feathers are reported as $\alpha$ - and $\beta$-keratin, encoded by multigene families (Shames and Sawyer 1987, Ng, Wu et al. 2014, Alibardi 2017). However, the components of $\alpha$-keratins are found in all vertebrates, while those of $\beta$-keratins are only observed in birds and reptiles. $\beta$-Keratin is unrelated to $\alpha$-keratin and likely emerged after divergence between the sauropsid and mammalian lineages (Alibardi and Sawyer 2002, Sawyer, Rogers et al. 2005, Wu, Irwin et al. 2008, Greenwold and Sawyer 2010, Fraser and Parry 2011, Strasser, Mlitz et al. 2014, Holthaus, Strasser et al. 2018). $\beta$-Keratins have been proposed to be renamed corneous $\beta$-proteins (CBPs) (Alibardi 2016, Holthaus, Eckhart et al. 2018); however, recent publications still conventionally refer to them as $\beta$-keratins (Chen, Juan et al. 2021, Lin, Lai et al. 2021, Lin, Liang et al. 2021, Saranathan, Narayanan et al. 2021, Zhang and Fan 2021).

$\beta$-keratins are mainly observed as infrastructural material expressed in the cortex, whereas $\alpha$ keratins are generally expressed in the medulla $(\mathrm{Ng}, \mathrm{Wu}$ et al. 2014). Both typical enhancers and temporospatial chromatin looping precisely regulate the expression of $\beta$-keratin gene clusters to establish the macro-regional specification of feathers and micro-level regional specification of feathers, respectively (Liang, Wu et al. 2020, Chen, Juan et al. 2021). An X-ray diffraction approach showed that the filament has a helical structure with four repeating units per turn, and hairpin turns in the $\beta$-sheet were also identified and shown to be unusually rich in proline residues (Fraser and Parry 2008). Furthermore, theoretical simulations predicted that the length of the $\beta$ keratin chain is typically 100-200 molecules and contains a central conserved region of approximately 34 amino acid residues, enabling the adoption of a twisted antiparallel $\beta$-sheet conformation with three central strands and two partial outer strands (Fraser and Parry 2011, Calvaresi, Eckhart et al. 2016)

PeerJ reviewing PDF | (2021:10:67226:1:1:NEW 14 Jan 2022) 
118

119

120

121

122

123

124

125

126

127

128

129

130

131

132

133

134

135

136

137

138

139

140

141

142

143

144

145

146

147

148

149

150

151

152

153

154

155

156

157

Most studies have applied cell biology approaches for exploring the protein composition of feathers or the structures of the polypeptide chain in the protein (Alibardi 2017), but it is still difficult to reveal the differences in related protein secondary structures (PSSs) among different types of feathers. Several studies have applied microbial biodegradation followed by scanning electron microscopy (SEM) measurements (Lingham-Soliar, Bonser et al. 2010, Lingham-Soliar 2014, Lingham-Soliar 2017), X-ray CT scanning (Laurent, Palmer et al. 2014, Chang, Wu et al. 2019, Laurent, Ahmed et al. 2020), infrared microspectroscopy (Tsuboi, Kaneuchi et al. 1991), or Raman spectroscopy (Tsuboi, Kaneuchi et al. 1991, Laurent, Dyke et al. 2020) to obtain morphological and PSS composition information in different positions in the rachises of various birds, but they have mainly focused on analyzing the microstructural architecture or $\beta$-pleated sheets of $\beta$-keratins.

Differences in the morphology, intrastructure, and composition of the feather shafts of birds have been proposed to correlate with different flight abilities and modes. Herein, we investigated the proportions of keratins and corneous proteins, which can be represented by PSSs and are likely to be affected by flying modes. Fourier transform infrared (FTIR) microspectroscopy is a state-ofthe-art technology that can be employed as a nondestructive analytical tool for obtaining the spatially resolved absorption of functional groups of biomolecules distributed within the area of interest in feather samples. Over decades, FTIR technologies have been widely utilized to analyze PSSs (Cai and Singh 1999, Lopez-Lorente and Mizaikoff 2016), and the molecular vibration frequencies of the main or side chain of the polypeptide can be resolved to elucidate the relationship between the percentages of PSSs and the flight modes of different species. The characteristic absorption bands of amide I (Am I) and amide II (Am II) are mainly attributed to carbonyl groups $(>\mathrm{C}=\mathrm{O})$ and $\mathrm{C}-\mathrm{N}-\mathrm{H}$ bonds of the peptide bonds for establishing PSSs by a hydrogen bonding framework in protein molecules; in particular, the Am I band has been widely used to resolve the different components of PSSs (Yang, Yang et al. 2015, Andrew Chan and Kazarian 2016, Lopez-Lorente and Mizaikoff 2016, Tucureanu, Matei et al. 2016). The absorption profile of the Am I band contains abundant information about PSSs, including $\alpha$-helix, $\beta$-sheet, $\beta$ turn, and random coil structures related to the carbonyl groups of peptide bonds in different physical and/or chemical environments in the frequency range of 1,720-1,580 $\mathrm{cm}^{-1}$. Moreover, PSSs in the Am I band can be unfolded by employing Fourier self-deconvolution and second derivatives of the absorption profile of the Am I band to quantitatively analyze the population of each PSS.

In addition to $\alpha$ - and $\beta$-keratin, collagen genes have been determined to be expressed in growing feathers ( $\mathrm{Ng}$, Chen et al. 2015). Collagen type I and type II are known to be involved in the feathering of chicken embryos (Mauger, Demarchez et al. 1982). Among them, collagen type $\mathrm{I}$ is the major protein in connective tissues and the most abundant protein in vertebrates. The structure of collagen consists of three-stranded, left-handed procollagen. Glycine forms a righthanded structure in which hydrogen bonds are entangled with each other. This feature of the triple helix can be observed in the infrared absorption spectrum at 1,637 cm-1 (Cooper and Knutson 1995, Belbachir, Noreen et al. 2009, Lee, Chiang et al. 2017). 
158

159

160

161

162

163

164

165

166

167

168

169

170

171

172

173

174

175

176

177

178

179

180

181

182

183

184

185

186

187

188

189

190

191

192

193

194

195

196

197

In this study, synchrotron-radiation-based Fourier transform infrared microspectroscopy (SRFTIRM) was employed to acquire spatially resolved FTIR spectra and to reveal the biomaterial composition distributed within the feather sections of the rachis cortex and medulla of seven species of birds using the Peak Resolve program in OMNIC ThermoFisher Scientific Inc., Waltham, MA, USA) to elucidate the PSSs. The initial value of the band center for each possible component of PSSs was found by the second derivative of the curve of the FTIR spectrum in the spectral range of $1720-1580 \mathrm{~cm}^{-1}$ of the feather sample. The spectral components of PSSs in the Am I band of the FTIR spectra acquired for feather samples from bird species were quantitatively calculated by iterating the curve-fitting process using a Gaussian function profile, and the line width of the full width at half maximum (FWHM) was set to $30 \mathrm{~cm}^{-}$

${ }^{1}$ for the initial fitting process in the Peak Resolve program. FTIR spectra were baseline-corrected before the process, and the curve fitting was processed by iteration in the calculation loop for adjusting parameter variables to minimize standard errors of the set of parameters, including FWHW, peak height, the peak position of the absorption component peaks, and the peak areas contributed from the corresponding absorption component peaks. Finally, the fitting result was obtained based on the previously mentioned parameters and each peak area of the corresponding components of PSSs.

The seven bird species investigated herein were chicken (Gallus gallus domesticus), mallard duck (Anas platyrhynchos), African sacred ibis (Threskiornis aethiopicus), crested goshawk (Accipiter trivirgatus), collared scops owl (Otus lettia), budgerigar (Melopsittacus undulatus), and zebra finch (Taeniopygia guttata). Using the flight feathers of these birds allowed us to detect the common basis of the proportions of birds with different flight modes.

\section{Materials \& Methods}

\section{Feather specimens}

All the feathers analyzed in this study were primary flight feathers, including domestic chicken (Gallus gallus domesticus), mallard duck (Anas platyrhynchos), African sacred ibis (Threskiornis aethiopicus), crested goshawk (Accipiter trivirgatus), collared scops owl (Otus lettia), budgerigar (Melopsittacus undulatus), and zebra finch (Taeniopygia guttata), to represent bird species with different flight modes. Primary flight feathers of domestic chickens and mallards were collected from an aviary at National Chung Hsing University. Primary flight feathers of budgerigar and zebra finch were collected from an aviary at National Tsing Hua University. Primary flight feathers of African sacred ibis, crested goshawk, and collared scops owl were plucked from the carcasses of wild individuals. The use of feathers from wild animals for research was approved by the Forestry Bureau of the Council of Agriculture of Taiwan (R.O.C.) under case no. $1091617349(4 / 22 / 2020)$.

\section{Paraffin-embedded feather sections}


198

199

200

201

202

203

204

205

206

207

208

209

210

211

212

213

214

215

216

217

218

219

220

221

222

223

224

225

226

227

228

229

230

231

232

233

234

235

236

The sectioned feather samples from a serial 5 - $\mu \mathrm{m}$ thick section of the paraffin embedding rachis of flight feathers were prepared for all species in this study. The rachis was soaked in liquid paraffin at temperatures in the range of $60 \sim 62{ }^{\circ} \mathrm{C}$ for 2 days. The paraffin-embedded rachis sectioned sample was transferred onto a Low-E slide (Kevley Technologies, Chesterfield, $\mathrm{OH}$, USA), and embedded paraffin of the rachis sample section was removed by xylene washing before SR-FTIR microspectroscopic mapping.

\section{EDC protein secondary structure prediction}

Expression profiles in feathers and protein sequences of the epidermal differentiation complex (EPC) of chickens were annotated from Lin et al. (2021). Secondary structures of EDC proteins were predicted using JPred4 (https://www.compbio.dundee.ac.uk/jpred/, accessed on 3 December 2021) (Drozdetskiy, Cole et al. 2015).

\section{Attenuated total reflection fourier transform infrared spectroscopy}

The attenuated total reflection Fourier transform infrared (ATR-FTIR) spectroscopy analysis system uses a modulated infrared beam to enter an infrared transparent crystal with a high refractive index in the spectral range $4000-650 \mathrm{~cm}^{-1}$ at $45^{\circ}$ of incidence. In this study, a highpressure clamp is utilized to pressure the rachis medulla and dorsal cortex sample to make contact with the surface of the ATR crystal (PIKE MIRacle ${ }^{\mathrm{TM}}$, 3-reflection diamond/ZnSe crystal). Furthermore, the evanescence wave of the modulated infrared beam occurs on the contact surface of the ATR crystal; the depth of penetration $(d p)$ of the propagating evanescence wave entering the sample ranges from approximately a hundred nanometers to several micrometers, as shown in the equation shown below; and the FTIR spectra of the feather samples were collected by using an FTIR spectrometer coupled with an LN-cooled MCT detector.

$$
\mathbb{d} p=\frac{\lambda}{2 \pi n_{1} \sqrt{\sin \theta-\left(n_{1} / n_{2}\right)^{2}}}
$$

where $\lambda$ is the wavelength of incident mid-infrared light, $\theta$ is the incident angle of the crystal, and $n_{1}$ and $n_{2}$ are the refractive indices of the sample and ATR crystal, respectively. The FTIR spectra were acquired in the range of $4,000-650 \mathrm{~cm}^{-1}$ and accumulated 128 scans at a spectral resolution of $4 \mathrm{~cm}^{-1}$. The penetration $(d p)$ of the infrared evanescent wave propagating into the sample was calculated to be approximately $2.15 \mu \mathrm{m}$ at wavenumber $1,650 \mathrm{~cm}^{-1}$ (the refractive index of the feather is approximately 1.55 ; the refractive index of the crystal is 2.4 ; the incident angle is $45^{\circ}$; and the wavelength is approximately 6.06 micrometers for wavenumber $1,650 \mathrm{~cm}^{-1}$ ). Three samples of flight feathers of each avian species were analyzed.

\section{Synchrotron-radiation-based Fourier transform infrared microspectroscopy}

The spectral maps of the sectioned flight feather samples were acquired at the SR-FTIRM endstation of TLS 14A1 of the National Synchrotron Radiation Research Center (NSRRC) in Taiwan, including an FTIR spectrometer (Nicolet 6700, ThermoFisher Scientific, Madison, WI, USA) coupled with a confocal infrared microscope (Nicolet Continuum; ThermoFisher Scientific, 
237

238

239

240

241

242

243

244

245

246

247

248

249

250

251

252

253

254

255

256

257

258

259

260

261

262

263

264

265

266

267

268

269

270

271

272

273

274

275

Madison, WI, USA). The detailed procedures of SR-FTIRM mapping experiments are described in Lee et al. (2017)(Lee, Chiang et al. 2017). The confocal aperture of the confocal infrared microscope was set to $15 \times 15 \mu \mathrm{m}^{2}$ and $10 \times 10 \mu \mathrm{m}^{2}$ of step size for roast scanning of the sample area of interest. The Am I band is the main characteristic absorption of carbonyl groups of the peptide bond framework, showing lower vibration wavenumbers than those of chemicals with carbonyl functional groups due to the hyperconjugation of peptide bonds and forming various PSSs by intermolecular and intramolecular hydrogen bonds. The percentages of corresponding PSSs of feather samples in the Am I band spanning the spectral range of 1,720-1,580 $\mathrm{cm}^{-1}$ were resolved by using the Peak Resolve function in $\mathrm{OMNIC}^{\mathrm{TM}}$. The automatic atmospheric suppression function in $\mathrm{OMNIC}^{\mathrm{TM}}$ was employed to eliminate the rovibrational absorption contributions from carbon dioxide and water in the ambient air. Three samples of flight feathers of each avian species were analyzed.

\section{Results}

The flight feather rachis is parameterized along the longitudinal direction of the shaft as the Z-axis $(Z)$, which was oriented along the shaft for the length from the proximal end at the SUR (superior umbilical region, junction of the calamus, and rachis) $(0.0 \mathrm{Z})$ to the distal tip (1.0 Z). The cross-section of the rachis of an avian feather of different species ranges from $0.2 \mathrm{Z}$ to $0.5 \mathrm{Z}$. (Fig. 1). The Am I band spanning the spectral range of 1,720-1,580 $\mathrm{cm}^{-1}$ was deconvoluted to resolve PSSs for the am I band of the feather rachis cortex, as shown in Fig. 2. The wavenumbers of the deconvoluted PSS components were assigned to $\beta$-turns $\left(1,614 \mathrm{~cm}^{-1}\right)$, parallel $\beta$-sheets $\left(1,627 \mathrm{~cm}^{-}\right.$ $\left.{ }^{1}\right)$, triple helix or $\beta$-sheets $\left(1,637 \mathrm{~cm}^{-1}\right)$, random coils $\left(1,648 \mathrm{~cm}^{-1}\right), \alpha$-helix $\left(1,657 \mathrm{~cm}^{-1}\right)$, $\beta$-turns $\left(1,668 \mathrm{~cm}^{-1}\right)$, parallel $\beta$-strand in $\beta$-sheets $\left(1,683 \mathrm{~cm}^{-1}\right)$, and anti-parallel $\beta$-strand in $\beta$-sheets $(1,693$ $\mathrm{cm}^{-1}$ ) (Petibois and Deleris 2006, Petibois, Gouspillou et al. 2006, Yang, Yang et al. 2015) (Fig. 3).

The cross-sectional flight feather rachises of seven avian species have corresponding characteristic shapes and unique anatomies (Fig. S1). The characteristic rectangular shape was observed in the cortex of the flight feather rachis for those in chicken, mallard, goshawk, budgerigar, and zebra finch. Interestingly, round or elliptical shapes of the cortex of flight feather rachises of sacred ibis and owls were identified. Furthermore, a foam-like medulla filled in the hollow space of the cortex of these flight feathers (Lingham-Soliar 2017, Wang and Meyers 2017 , Chang, $\mathrm{Wu}$ et al. 2019, Deng, Kovalev et al. 2021). The morphological structures of the flight feather medulla differ among these species; for example, the structure in the medulla in the flight feathers of sustained flyers and birds of prey shows a V-ridge shape, and the characteristic hollow shape is observed on the dorsal part of the medulla, suggesting that the organization of the medulla is critical for providing mechanical support (Chang, Wu et al. 2019).

Peer) reviewing PDF | (2021:10:67226:1:1:NEW 14 Jan 2022) 
276 Spectral specificity of the cortex and medulla using attenuated total reflection Fourier 277 transform infrared (ATR-FTIR) spectroscopy

278

279

280

281

282

283

284

285

286

287

288

289

290

291

292

293

294

295

296

297

298

299

300

301

302

303

304

305

306

307

308

309

310

311

312

313

314

315

The ratio of the absorption component band of the calculated PSS to the total area of Am I is shown in Fig. 3 (Fig. S2 \& S3). In general, all medulla and cortex samples showed strong absorption attributed to PSS $\beta$-sheets, and $\beta$-keratins are well understood as major components of feathers. Additionally, the peak area percentage of approximately $10 \sim 15 \%$ attributed to characteristic absorption of the triple helix for collagen was resolved in the Am I band, consistent with the genomic expression of DNA related to collagens ( $\mathrm{Ng}$, Chen et al. 2015). Two characteristic absorption bands spanning the range of 1,641-1,623 $\mathrm{cm}^{-1}$ and the range of 1,695$1,670 \mathrm{~cm}^{-1}$ have been indicated as an antiparallel $\beta$-strand in a $\beta$-sheet structure for keratin (Zhang, Senak et al. 2011). Therefore, the peak-height ratio $\mathrm{H}_{1,695} / \mathrm{H}_{1,630}$ was suggested to be proportional to the relative distribution of the antiparallel $\beta$-strand component $\left(1,695 \mathrm{~cm}^{-1}\right)$ to the parallel $\beta$ strand component $\left(1,630 \mathrm{~cm}^{-1}\right)$ in a $\beta$-sheet structure (Chirgadze and Nevskaya 1976). Previous studies of pelican and seagull feathers showed that the $\beta$-sheets primarily existed in the antiparallel conformation (Fraser and Suzuki 1965). Collectively, the $\beta$-sheet structure was expected to be dominant in these feather samples. Although some epidermal differentiation complex (EDC) genes are expressed in feathers (Lin, Lai et al. 2021), most EDC members, especially those higly expressed in feathers, do not contain distinct secondary structures in predictions (Table S1).

The calculated peak area of the $\alpha$-helix structure was approximately 9-12\% in the Am I band for all feather samples; hence, we proposed that $\alpha$-keratins might develop in mature flight feathers (Figure 4). $\beta$-sheet structures were observed in the $\alpha$-keratin filaments, which were suggested to increase the mechanical strength of feathers (Parry and North 1998, Parry, Marekov et al. 2002, Kreplak, Doucet et al. 2004) to reduce stress during flight. Therefore, the content of $\alpha$-keratins would be underestimated by the suggestion of only $\alpha$-helix contribution in the structure of $\alpha$ keratins. Based on our findings, the structure of $\beta$-sheets developed from $\alpha$ - and $\beta$-keratins plays an essential role in higher levels of assembly and in determining their mechanical properties (Fraser and Parry 2009). The helical content was slightly higher in the flight feather cortex of chickens, ducks, and sacred ibis than in the medulla but was slightly lower in the flight feather cortex of goshawk, owl, budgerigar, and zebra finch (Table S2).

In addition, we also estimated proteins other than $\alpha$ - and $\beta$-keratins, in which distinct features are observed in the FTIR spectrum. The calculated contribution of the triple-helix structure in the Am I band was characteristic absorption for collagen type I; the other absorption bands were observed at $3,279 \mathrm{~cm}^{-1}, 3,052 \mathrm{~cm}^{-1}, 1,545 \mathrm{~cm}^{-1}, 1,292 \mathrm{~cm}^{-1}$, and $1,260 \mathrm{~cm}^{-1}$ and assigned to amide A, amide B, Am II, and amide III (Am III) bands, respectively (Figure 2). In the study, the calculated results showed that the cortex of the flight feather might contain $11-16 \%$ collagen, whereas the medulla contained $13-16 \%$ collagen. The collagen content was slightly higher in the medulla than in the cortex, except for budgerigar and zebra finch.

\section{Spectral map of PSSs of feather rachis sections}

Peer) reviewing PDF | (2021:10:67226:1:1:NEW 14 Jan 2022) 
We extended the investigation of PSSs of proteins packed within the medulla by using lateralresolved synchrotron-radiation-based Fourier transform infrared microspectroscopy (SR-FTIRM). The flight feather rachis samples of each species were sectioned by a series of continuous sectioning of the same rachis position, and herein, three cross-section samples were prepared and analyzed for each species. Lateral-resolved FTIR spectral images were constructed by using the peak height of the Am I band for the feather shaft medulla of seven species of birds, as shown in Fig. 5. The absorbance of the Am I band of the medulla for these birds varied among different regions, consistent with the suggestion of the varied density of packed cells in regions (Chang, $\mathrm{Wu}$ et al. 2019) (Fig. S4-S10), so that corneous protein was not evenly distributed in the medulla. The relative population of PSSs, such as $\alpha$-helices, $\beta$-sheets, triple-helices, and random coil secondary structures, can be resolved by using Peak Resolve software in OMNIC ${ }^{\circledR}$. The analysis of the FTIR spectra of cross-section samples showed that a higher percentage of amino acids can be expected for $\alpha$-helical peptides developed within the medulla cells of the flight feathers than has been reported and is not usually observed in $\beta$-sheet peptides $(\mathrm{Ng}$, Wu et al. 2012) (Fig. S8).

\section{Discussion}

\section{$\alpha$ - and $\beta$-keratins of the medulla and cortex in different bird species}

In this study, the accumulation of $\alpha$ - and $\beta$-keratins was observed in different parts of the rachis and ramus. $\alpha$-Keratin has an important role in the early formation of rachises, barbs, and barbules, although feather- $\beta$-keratins are the major component of feathers. A deletion in two $\alpha$ keratin genes (KRT75L4 and KRT6A (previously referred to as KRT75)) is associated with the frizzled feather phenotype ( $\mathrm{Ng}, \mathrm{Wu}$ et al. 2012, Dong, He et al. 2018). The rachis medulla with a defect in the KRT6A (previously known as the KRT75 gene) gene would cause the rigidity of feathers to decrease due to incomplete development and the rachis to bend ( $\mathrm{Ng}, \mathrm{Wu}$ et al. 2012). Despite this progress, few studies have revealed how the rachis becomes structured.

Cytoplasmic networks of intermediate filaments were built by obligate heteropolymers of types I and II $\alpha$-keratins. The cornification process of claws, scales, beaks, and feathers of birds requires the deposition of $\beta$-keratins onto scaffolds of epidermal $\alpha$-keratin filaments (Alibardi 2013). Transcriptomic and evolutionary analyses were facilitated by manual annotation and curation of $\alpha$ - and $\beta$-keratin genes in avian genomes (Greenwold and Sawyer 2010, Greenwold, Bao et al. 2014, Ng, Wu et al. 2014), suggesting that various combinations of $\alpha$ - and $\beta$-keratins contribute to morphological and structural diversity among avian epidermal appendages, with intrafeather differences largely attributed to differential expression of feather- $\beta$-keratins (Greenwold, Bao et al. 2014, Ng, Wu et al. 2014, Wu, Ng et al. 2015).

The flight feather cortex of ibis, goshawk, owl, budgerigar, and zebra finch contains higher helical content in the cortex of the flight feather than in the medulla compared to chickens and ducks who mainly live on the ground (Supplementary Table 1). Goshawks and owls spend more time in woodlands and initiate mainly attacks on their prey from perches, whereas zebra finches and budgerigars are flappers with excellent maneuverability. Their flight feathers should endure stronger mechanical forces acting on the cortex in a short time. Higher contents of $\alpha$-keratin may 
356

357

358

359

360

361

362

363

364

365

366

367

368

369

370

371

372

373

374

375

376

377

378

379

380

381

382

383

384

385

386

387

388

389

390

391

392

393

394

suggest that the mechanical properties provided by $\alpha$-keratins in the cortex of flight feathers may have been previously disregarded. Further studies, including more avian species sampled from wide ranges of phylogenetic lineages, are required to perform a solid comparison of PSSs in birds of different flight modes.

Although it has been reported that unfavorable conditions such as nutrient-poor conditions in captivity during molting may affect the quality of avian feathers in some species of birds (Murphy, King et al. 1988, Dawson, Hinsley et al. 2000), we can eliminate this possibility because we did not observe that feathers from aviaries (chickens, ducks, budgerigar, and zebra finch) are significantly different from those derived from the wild (ibises, goshawks, and owls). Additionally, birds kept in aviaries are either domesticated birds or pet birds and should already be well adapted to artificial environments.

\section{Collagen in the rachis}

The FTIR spectra of the medulla of the feather rachis revealed crucial spectral evidence for collagen type I, as strongly supported by the characteristic absorption of the Am III band of protein in the range of 1,290-1,260 $\mathrm{cm}^{-1}$, glycan residual (oligosaccharide residue) chemically attached to collagen in the range of 1,200-900 $\mathrm{cm}^{-1}$, and triple-helix resolved at 1,637 $\mathrm{cm}^{-1}$ in Am I band (Cooper and Knutson 1995, Belbachir, Noreen et al. 2009, Lee, Chiang et al. 2017). Based on these findings, we strongly suggested that collagen type I develops in the medulla of the feather rachis.

Collagen genes are differentially expressed in regenerating feathers of different morphotypes (Ng, Chen et al. 2015), and collagens might play morphogenetic roles during embryonic feather development (Mauger, Demarchez et al. 1982). Type VI collagen is regulated by mesenchymal cell behaviors during early feather development in embryonic chickens (Kobayashi, Fukunaga et al. 2005). The distribution of collagen types I, III, and V becomes heterogeneous during the formation of placode and disappears from the apex of growing feather buds, while their collagen fiber becomes denser in the rudiment (Sengel 1990). Collagens have been proposed to have critical roles in the development of feather rudiments (Goetinck and Sekellick 1972). However, the role of collagen in mature feathers needs further investigation, so it is interesting to determine if collagens play a mechanistic role in feathers.

\section{Feather rachis morphology}

The medulla of the rachis is composed of keratinocytes that are developed to grow into hollow, spongy, and porous structures (Sullivan, Hung et al. 2019). The types of keratinocytes also develop into different growth directions, pore sizes, and pore shapes; furthermore, different pore sizes and medullary arrangements are well understood in the feather shaft medulla for birds with different flight abilities and flight modes (Chang, Wu et al. 2019). The ratio of the diameter of the average pore size to the weight in the medulla of the sparrows that flutter quickly is relatively high, while the elongation and orientation angles of aligned cell bands in the medulla of the soaring flight differ from those of other species. 
395

396

397

398

399

400

401

402

403

404

405

406

407

408

409

410

411

412

413

414

415

416

417

418

419

420

421

422

423

424

425

426

427

428

429

430

431

432

433

Based on our findings, a greater area of the hollow cell depletion zone was observed in the medulla of the cross-section feather shaft, which may enable the feathers to resist greater mechanical stresses during flight, especially for birds with a better flight ability (Wang and Meyers 2017, Chang, Wu et al. 2019). In addition, the cortex of the shaft of sustained flyers also tends to be thicker on dorsal and ventral sides and thinner on lateral sides (Wang and Meyers 2017, Wang and Sullivan 2017, Chang, Wu et al. 2019). Accordingly, this may represent the difference in the medulla or cortical structure of the feather shafts of birds with various flight modes, giving them different flight abilities.

\section{Conclusions}

In this study, ATR-FTIR spectroscopy and SR-FTIRM were applied to resolve the components of PSSs and to provide spectral images for cross-sectioned feather samples with the two-dimensional distribution of the Am I band in flight feathers of several avian species. We observed the ratio of $\alpha$-keratins/ $\beta$-keratins and collagens in both the cortex and medulla of flight feathers based on the information extracted from the Am I bands. A significant amount of $\alpha$ keratins and collagens has been detected in flight feather shafts, and these proteins vary in birds with different flight abilities, suggesting that they may contribute to different mechanical properties. Both SR-FTIRM and ATR-FTIR are nondestructive methods and provide powerful methods for understanding the content and distribution of these structural proteins in mature feathers.

\section{Acknowledgments}

We thank Profs. Chih-Feng Chen and Si-Min Lin, the Raptor Research Group of Taiwan, and Taipei Zoo for providing us with essential feather samples. Profs. Wen-Tau Juan and Po-Yu Chen provided excellent suggestions.

\section{References}

Alibardi, L. (2013). "Cornification in reptilian epidermis occurs through the deposition of keratinassociated beta-proteins (beta-keratins) onto a scaffold of intermediate filament keratins." $\underline{\mathrm{J}}$ Morphol 274(2): 175-193.

Alibardi, L. (2016). "The Process of Cornification Evolved From the Initial Keratinization in the Epidermis and Epidermal Derivatives of Vertebrates: A New Synthesis and the Case of Sauropsids." Int Rev Cell Mol Biol 327: 263-319.

Alibardi, L. (2017). "Review: cornification, morphogenesis and evolution of feathers." Protoplasma 254(3): 1259-1281. 
434

435

436

437

438

439

440

441

442

443

444

445

446

447

448

449

450

451

452

453

454

455

456

457

458

459

460

461

462

463

464

465

466

467

468

469

470

471

472

473

474

475

476

477

478

479

480

481

482

483

484

Alibardi, L. and R. H. Sawyer (2002). "Immunocytochemical analysis of beta keratins in the epidermis of chelonians, lepidosaurians, and archosaurians." J Exp Zool 293(1): 27-38.

Andrew Chan, K. L. and S. G. Kazarian (2016). "Attenuated total reflection Fourier-transform infrared (ATR-FTIR) imaging of tissues and live cells." Chem Soc Rev 45(7): 1850-1864.

Aparicio, J. M., R. Bonal and P. J. Cordero (2003). "Evolution of the structure of tail feathers: implications for the theory of sexual selection." Evolution 57(2): 397-405.

Bachmann, T., J. Emmerlich, W. Baumgartner, J. M. Schneider and H. Wagner (2012). "Flexural stiffness of feather shafts: geometry rules over material properties." J Exp Biol 215(3): 405-415. Belbachir, K., R. Noreen, G. Gouspillou and C. Petibois (2009). "Collagen types analysis and differentiation by FTIR spectroscopy." Anal Bioanal Chem 395(3): 829-837.

Bonser, R. and P. Purslow (1995). "The Young's modulus of feather keratin." J Exp Biol 198(Pt 4): 1029-1033.

Cai, S. and B. R. Singh (1999). "Identification of beta-turn and random coil amide III infrared bands for secondary structure estimation of proteins." Biophys Chem 80(1): 7-20.

Calvaresi, M., L. Eckhart and L. Alibardi (2016). "The molecular organization of the beta-sheet region in Corneous beta-proteins (beta-keratins) of sauropsids explains its stability and polymerization into filaments." J Struct Biol 194(3): 282-291.

Chang, W. L., H. Wu, Y. K. Chiu, S. Wang, T. X. Jiang, Z. L. Luo, Y. C. Lin, A. Li, J. T. Hsu, H. L. Huang, H. J. Gu, T. Y. Lin, S. M. Yang, T. T. Lee, Y. C. Lai, M. X. Lei, M. Y. Shie, C. T. Yao, Y. W. Chen, J. C. Tsai, S. J. Shieh, Y. K. Hwu, H. C. Cheng, P. C. Tang, S. C. Hung, C. F. Chen, M. Habib, R. B. Widelitz, P. Wu, W. T. Juan and C. M. Chuong (2019). "The Making of a Flight Feather: Bio-architectural Principles and Adaptation." Cell 179(6): 1409-+.

Chen, C. F., J. Foley, P. C. Tang, A. Li, T. X. Jiang, P. Wu, R. B. Widelitz and C. M. Chuong (2015). "Development, regeneration, and evolution of feathers." Annu Rev Anim Biosci 3: 169195.

Chen, C. K., W. T. Juan, Y. C. Liang, P. Wu and C. M. Chuong (2021). "Making region-specific integumentary organs in birds: evolution and modifications." Curr Opin Genet Dev 69: 103-111. Chirgadze, Y. N. and N. A. Nevskaya (1976). "Infrared spectra and resonance interaction of amide-I vibration of the antiparallel-chain pleated sheet." Biopolymers 15(4): 607-625.

Chuong, C. M., P. Wu, F. C. Zhang, X. Xu, M. Yu, R. B. Widelitz, T. X. Jiang and L. Hou (2003). "Adaptation to the sky: Defining the feather with integument fossils from mesozoic China and experimental evidence from molecular laboratories." J Exp Zool B Mol Dev Evol 298(1): 42-56. Cooper, E. A. and K. Knutson (1995). "Fourier transform infrared spectroscopy investigations of protein structure." Pharm Biotechnol 7: 101-143.

Dawson, A., S. A. Hinsley, P. N. Ferns, R. H. Bonser and L. Eccleston (2000). "Rate of moult affects feather quality: a mechanism linking current reproductive effort to future survival." Proc Biol Sci 267(1457): 2093-2098.

Deng, K., A. Kovalev, H. Rajabi, C. F. Schaber, Z. D. Dai and S. N. Gorb (2021). "The damping properties of the foam-filled shaft of primary feathers of the pigeon Columba livia." Naturwissenschaften 109(1): 1.

Dong, J., C. He, Z. Wang, Y. Li, S. Li, L. Tao, J. Chen, D. Li, F. Yang, N. Li, Q. Zhang, L. Zhang, G. Wang, F. Akinyemi, H. Meng and B. Du (2018). "A novel deletion in KRT75L4 mediates the frizzle trait in a Chinese indigenous chicken." Genet Sel Evol 50(1): 68.

Drozdetskiy, A., C. Cole, J. Procter and G. J. Barton (2015). "JPred4: a protein secondary structure prediction server." Nucleic Acids Res 43(W1): W389-394.

Ennos, A., J. Hickson and A. Roberts (1995). "Functional morphology of the vanes of the flight feathers of the pigeon Columba livia." J Exp Biol 198(5): 1219-1228.

Feo, T. J., D. J. Field and R. O. Prum (2015). "Barb geometry of asymmetrical feathers reveals a transitional morphology in the evolution of avian flight." Proc Biol Sci 282(1803): 20142864. Fraser, R. D. and D. A. Parry (2008). "Molecular packing in the feather keratin filament." J Struct Biol 162(1): 1-13.

Peer] reviewing PDF | (2021:10:67226:1:1:NEW 14 Jan 2022) 
485 Fraser, R. D. and D. A. Parry (2011). "The structural basis of the filament-matrix texture in the

486

487

488

489

490

491

492

493

494

495

496

497

498

499

500

501

502

503

504

505

506

507

508

509

510

511

512

513

514

515

516

517

518

519

520

521

522

523

524

525

526

527

528

529

530

531

532

533

534 avian/reptilian group of hard beta-keratins." J Struct Biol 173(2): 391-405.

Fraser, R. D. and E. Suzuki (1965). "Polypeptide chain conformation in feather keratin." J Mol Biol 14(1): 279-282.

Fraser, R. D. B. and D. A. D. Parry (2009). "The role of beta-sheets in the structure and assembly of keratins." Biophys Rev 1(1): 27.

Goetinck, P. F. and M. J. Sekellick (1972). "Observations on collagen synthesis, lattice formation, and morphology of scaleless and normal embryonic skin." Dev Biol 28(4): 636-648.

Greenwold, M. J., W. Bao, E. D. Jarvis, H. Hu, C. Li, M. T. Gilbert, G. Zhang and R. H. Sawyer (2014). "Dynamic evolution of the alpha (alpha) and beta (beta) keratins has accompanied integument diversification and the adaptation of birds into novel lifestyles." BMC Evol Biol 14: 249.

Greenwold, M. J. and R. H. Sawyer (2010). "Genomic organization and molecular phylogenies of the beta (beta) keratin multigene family in the chicken (Gallus gallus) and zebra finch (Taeniopygia guttata): implications for feather evolution." BMC Evol Biol 10: 148.

Holthaus, K. B., L. Eckhart, L. Dalla Valle and L. Alibardi (2018). "Review: Evolution and diversification of corneous beta-proteins, the characteristic epidermal proteins of reptiles and birds." J Exp Zool B Mol Dev Evol 330(8): 438-453.

Holthaus, K. B., B. Strasser, J. Lachner, S. Sukseree, W. Sipos, A. Weissenbacher, E. Tschachler, L. Alibardi and L. Eckhart (2018). "Comparative Analysis of Epidermal Differentiation Genes of Crocodilians Suggests New Models for the Evolutionary Origin of Avian Feather Proteins." Genome Biol Evol 10(2): 694-704.

Kobayashi, K., S. Fukunaga, K. Takenouchi, Y. Kato-mori and F. Nakamura (2005). "Functional role of type VI collagen during early feather development of the chicken embryo in vitro." Anim Sci J 76(3): 273-282.

Kovalev, A., A. E. Filippov and S. N. Gorb (2014). "Unzipping bird feathers." J R Soc Interface 11(92): 20130988.

Kreplak, L., J. Doucet, P. Dumas and F. Briki (2004). "New aspects of the alpha-helix to betasheet transition in stretched hard alpha-keratin fibers." Biophys J 87(1): 640-647.

Laurent, C., S. Ahmed, R. Boardman, R. Cook, G. Dyke, C. Palmer, P. Schneider and D. E. K. $\mathrm{R}$ (2020). "Imaging techniques for observing laminar geometry in the feather shaft cortex." $\underline{J}$ Microsc 277(3): 154-159.

Laurent, C. M., J. M. Dyke, R. B. Cook, G. Dyke and R. de Kat (2020). "Spectroscopy on the wing: Investigating possible differences in protein secondary structures in feather shafts of birds using Raman spectroscopy." J Struct Biol 211(1): 107529.

Laurent, C. M., C. Palmer, R. P. Boardman, G. Dyke and R. B. Cook (2014). "Nanomechanical properties of bird feather rachises: exploring naturally occurring fibre reinforced laminar composites." J R Soc Interface 11(101): 20140961.

Lee, Y. C., C. C. Chiang, P. Y. Huang, C. Y. Chung, T. D. Huang, C. C. Wang, C. I. Chen, R. S. Chang, C. H. Liao and R. R. Reisz (2017). "Evidence of preserved collagen in an Early Jurassic sauropodomorph dinosaur revealed by synchrotron FTIR microspectroscopy." Nat Commun 8: 14220.

Lees, J., T. Garner, G. Cooper and R. Nudds (2017). "Rachis morphology cannot accurately predict the mechanical performance of primary feathers in extant (and therefore fossil) feathered flyers." R Soc Open Sci 4(2): 160927.

Liang, Y. C., P. Wu, G. W. Lin, C. K. Chen, C. Y. Yeh, S. Tsai, J. Yan, T. X. Jiang, Y. C. Lai, D. Huang, M. Cai, R. Choi, R. B. Widelitz, W. Lu and C. M. Chuong (2020). "Folding Keratin Gene Clusters during Skin Regional Specification." Dev Cell 53(5): 561-576 e569.

Lin, G. W., Y. C. Lai, Y. C. Liang, R. B. Widelitz, P. Wu and C. M. Chuong (2021). "Regional Specific Differentiation of Integumentary Organs: Regulation of Gene Clusters within the Avian

Peer) reviewing PDF | (2021:10:67226:1:1:NEW 14 Jan 2022) 
535 Epidermal Differentiation Complex and Impacts of SATB2 Overexpression." Genes (Basel)

536

537

538

539

540

541

542

543

544

545

546

547

548

549

550

551

552

553

554

555

556

557

558

559

560

561

562

563

564

565

566

567

568

569

570

571

572

573

574

575

576

577

578

579

580

581

582

583

584
12(8).

Lin, G. W., Y. C. Liang, P. Wu, C. K. Chen, Y. C. Lai, T. X. Jiang, Y. H. Haung and C. M. Chuong (2021). "Regional specific differentiation of integumentary organs: SATB2 is involved in alpha- and beta-keratin gene cluster switching in the chicken." Dev Dyn.

Lingham-Soliar, T. (2014). "Feather structure, biomechanics and biomimetics: the incredible lightness of being." Journal of Ornithology 155(2): 323-336.

Lingham-Soliar, T. (2017). "Microstructural tissue-engineering in the rachis and barbs of bird feathers." Sci Rep 7: 45162.

Lingham-Soliar, T., R. H. Bonser and J. Wesley-Smith (2010). "Selective biodegradation of keratin matrix in feather rachis reveals classic bioengineering." Proc Biol Sci 277(1685): 11611168.

Lopez-Lorente, A. I. and B. Mizaikoff (2016). "Mid-infrared spectroscopy for protein analysis: potential and challenges." Anal Bioanal Chem 408(11): 2875-2889.

Mauger, A., M. Demarchez, D. Herbage, J. A. Grimaud, M. Druguet, D. Hartmann and P. Sengel (1982). "Immunofluorescent localization of collagen types I and III, and of fibronectin during feather morphogenesis in the chick embryo." Dev Biol 94(1): 93-105.

Murphy, M. E., J. R. King and J. Lu (1988). "Malnutrition during the Postnuptial Molt of WhiteCrowned Sparrows - Feather Growth and Quality." Can J Zool 66(6): 1403-1413.

Ng, C. S., C. K. Chen, W. L. Fan, P. Wu, S. M. Wu, J. J. Chen, Y. T. Lai, C. T. Mao, M. Y. Lu, D. R. Chen, Z. S. Lin, K. J. Yang, Y. A. Sha, T. C. Tu, C. F. Chen, C. M. Chuong and W. H. Li (2015). "Transcriptomic analyses of regenerating adult feathers in chicken." BMC Genomics 16: 756.

Ng, C. S. and W. H. Li (2018). "Genetic and Molecular Basis of Feather Diversity in Birds." Genome Biol Evol 10(10): 2572-2586.

Ng, C. S., P. Wu, W. L. Fan, J. Yan, C. K. Chen, Y. T. Lai, S. M. Wu, C. T. Mao, J. J. Chen, M. Y. Lu, M. R. Ho, R. B. Widelitz, C. F. Chen, C. M. Chuong and W. H. Li (2014). "Genomic organization, transcriptomic analysis, and functional characterization of avian alpha- and betakeratins in diverse feather forms." Genome Biol Evol 6(9): 2258-2273.

Ng, C. S., P. Wu, J. Foley, A. Foley, M. L. McDonald, W. T. Juan, C. J. Huang, Y. T. Lai, W. S. Lo, C. F. Chen, S. M. Leal, H. Zhang, R. B. Widelitz, P. I. Patel, W. H. Li and C. M. Chuong (2012). "The chicken frizzle feather is due to an alpha-keratin (KRT75) mutation that causes a defective rachis." PLoS Genet 8(7): e1002748.

Osvath, G., O. Vincze, D. C. David, L. J. Nagy, A. Z. Lendvai, R. L. Nudds and P. L. Pap (2020). "Morphological characterization of flight feather shafts in four bird species with different flight styles." Biol J Linn Soc 131(1): 192-202.

Pap, P. L., G. Osvath, K. Sandor, O. Vincze, L. Barbos, A. Marton, R. L. Nudds and C. I. Vagasi (2015). "Interspecific variation in the structural properties of flight feathers in birds indicates adaptation to flight requirements and habitat." Funct Ecol 29(6): 746-757.

Parry, D. A., L. N. Marekov, P. M. Steinert and T. A. Smith (2002). "A role for the 1A and L1 rod domain segments in head domain organization and function of intermediate filaments: structural analysis of trichocyte keratin." J Struct Biol 137(1-2): 97-108.

Parry, D. A. and A. C. North (1998). "Hard alpha-keratin intermediate filament chains:

substructure of the $\mathrm{N}$ - and $\mathrm{C}$-terminal domains and the predicted structure and function of the Cterminal domains of type I and type II chains." J Struct Biol 122(1-2): 67-75.

Petibois, C. and G. Deleris (2006). "Chemical mapping of tumor progression by FT-IR imaging: towards molecular histopathology." Trends Biotechnol 24(10): 455-462.

Petibois, C., G. Gouspillou, K. Wehbe, J. P. Delage and G. Deleris (2006). "Analysis of type I and IV collagens by FT-IR spectroscopy and imaging for a molecular investigation of skeletal muscle connective tissue." Anal Bioanal Chem 386(7-8): 1961-1966. 
585 Prum, R. O. and A. H. Brush (2002). "The evolutionary origin and diversification of feathers." $\underline{Q}$ 586 Rev Biol 77(3): 261-295.

587 Rayner, J. M. (1982). "Avian flight energetics." Annu Rev Physiol 44: 109-119.

588

589

590

591

592

593

594

595

596

597

598

599

600

601

602

603

604 Saranathan, V., S. Narayanan, A. Sandy, E. R. Dufresne and R. O. Prum (2021). "Evolution of single gyroid photonic crystals in bird feathers." Proc Natl Acad Sci U S A 118(23).

Sawyer, R. H., L. Rogers, L. Washington, T. C. Glenn and L. W. Knapp (2005). "Evolutionary origin of the feather epidermis." Dev Dyn 232(2): 256-267.

Sengel, P. (1990). "Pattern formation in skin development." Int J Dev Biol 34(1): 33-50.

Shames, R. B. and R. H. Sawyer (1987). "Expression of beta-keratin genes during development of avian skin appendages." Curr Top Dev Biol 22: 235-253.

Strasser, B., V. Mlitz, M. Hermann, R. H. Rice, R. A. Eigenheer, L. Alibardi, E. Tschachler and L. Eckhart (2014). "Evolutionary origin and diversification of epidermal barrier proteins in amniotes." Mol Biol Evol 31(12): 3194-3205.

Sullivan, T. N., T. T. Hung, A. Velasco-Hogan and M. A. Meyers (2019). "Bioinspired avian feather designs." Mat Sci Eng C-Mater 105.

Sullivan, T. N., M. A. Meyers and E. Arzt (2019). "Scaling of bird wings and feathers for efficient flight." Sci Adv 5(1): eaat4269.

Sullivan, T. N., A. Pissarenko, S. A. Herrera, D. Kisailus, V. A. Lubarda and M. A. Meyers (2016). "A lightweight, biological structure with tailored stiffness: The feather vane." Acta Biomater 41: 27-39.

605

606

607

608

609

610

611

612

613

614

615

616

617

618

619

620

621

622

623

624

625

626

627

628

629

630

631

632

Sullivan, T. N., B. Wang, H. D. Espinosa and M. A. Meyers (2017). "Extreme lightweight structures: avian feathers and bones." Mater Today 20(7): 377-391.

Tsuboi, M., F. Kaneuchi, T. Ikeda and K. Akahane (1991). "Infrared and Raman Microscopy of Fowl Feather Barb." Can J Chem 69(11): 1752-1757.

Tucureanu, V., A. Matei and A. M. Avram (2016). "FTIR Spectroscopy for Carbon Family Study." Crit Rev Anal Chem 46(6): 502-520.

Wang, B. and M. A. Meyers (2017). "Light Like a Feather: A Fibrous Natural Composite with a Shape Changing from Round to Square." Adv Sci (Weinh) 4(3): 1600360.

Wang, B. and T. N. Sullivan (2017). "A review of terrestrial, aerial and aquatic keratins: the structure and mechanical properties of pangolin scales, feather shafts and baleen plates." $\underline{\mathrm{J}}$ Mech Behav Biomed 76: 4-20.

Wang, X., R. L. Nudds, C. Palmer and G. J. Dyke (2012). "Size scaling and stiffness of avian primary feathers: implications for the flight of Mesozoic birds." J Evol Biol 25(3): 547-555.

Weber, T. P., S. Kranenbarg, A. Hedenstrom, J. H. Waarsing and H. Weinans (2010). "Flight feather shaft structure of two warbler species with different moult schedules: a study using highresolution X-ray imaging." J Zool 280(2): 163-170.

Weiss, I. M., K. P. Schmitt and H. O. Kirchner (2011). "The peacock's train (Pavo cristatus and Pavo cristatus mut. alba) II. The molecular parameters of feather keratin plasticity." J Exp Zool A Ecol Genet Physiol 315(5): 266-273.

Worcester, S. E. (1996). "The scaling of the size and stiffness of primary flight feathers." J Zool 239: 609-624.

Wu, D. D., D. M. Irwin and Y. P. Zhang (2008). "Molecular evolution of the keratin associated protein gene family in mammals, role in the evolution of mammalian hair." BMC Evol Biol 8: 241. Wu, P., C. S. Ng, J. Yan, Y. C. Lai, C. K. Chen, Y. T. Lai, S. M. Wu, J. J. Chen, W. Luo, R. B. Widelitz, W. H. Li and C. M. Chuong (2015). "Topographical mapping of alpha- and betakeratins on developing chicken skin integuments: Functional interaction and evolutionary perspectives." Proc Natl Acad Sci U S A 112(49): E6770-6779.

633

Xu, X., Z. Zhou, R. Dudley, S. Mackem, C. M. Chuong, G. M. Erickson and D. J. Varricchio (2014). "An integrative approach to understanding bird origins." Science 346(6215): 1253293.

Peer) reviewing PDF | (2021:10:67226:1:1:NEW 14 Jan 2022) 
634 Yang, H., S. Yang, J. Kong, A. Dong and S. Yu (2015). "Obtaining information about protein

635 secondary structures in aqueous solution using Fourier transform IR spectroscopy." Nat Protoc

636 10(3): 382-396.

637 Zhang, F., L. Jiang and S. Wang (2018). "Repairable cascaded slide-lock system endows bird

638 feathers with tear-resistance and superdurability." Proc Natl Acad Sci U S A 115(40): 10046-

63910051.

640 Zhang, G. J., L. Senak and D. J. Moore (2011). "Measuring changes in chemistry, composition,

641 and molecular structure within hair fibers by infrared and Raman spectroscopic imaging." $\mathrm{J}$

642 Biomed Opt 16(5).

643 Zhang, W. and Y. Fan (2021). "Structure of Keratin." Methods Mol Biol 2347: 41-53.

644 Zou, M., J. Zhou, L. Xu, J. Song, S. Liu and X. Li (2019). "An engineering perspective on the

645 microstructure and compression properties of the seagull Larus argentatus feather rachis."

646 Micron 126: 102735.

647 
Figure 1

The external and internal structure of the feather shaft of a bird

(A) Feathers of domestic chickens. The shaft of flight feathers can be divided into two parts:

rachis and calamus. $0.0 \mathrm{Z}$ to $1.0 \mathrm{Z}$ represents the one-dimensional position of the rachis from the proximal part to the distal part, and $0.4 \mathrm{Z}$ is the position of the slice in the figure. (B) $\mathrm{A}$ slice of the rachis $(0.4 \mathrm{Z})$. The rachis has two parts: cortex and medulla. 

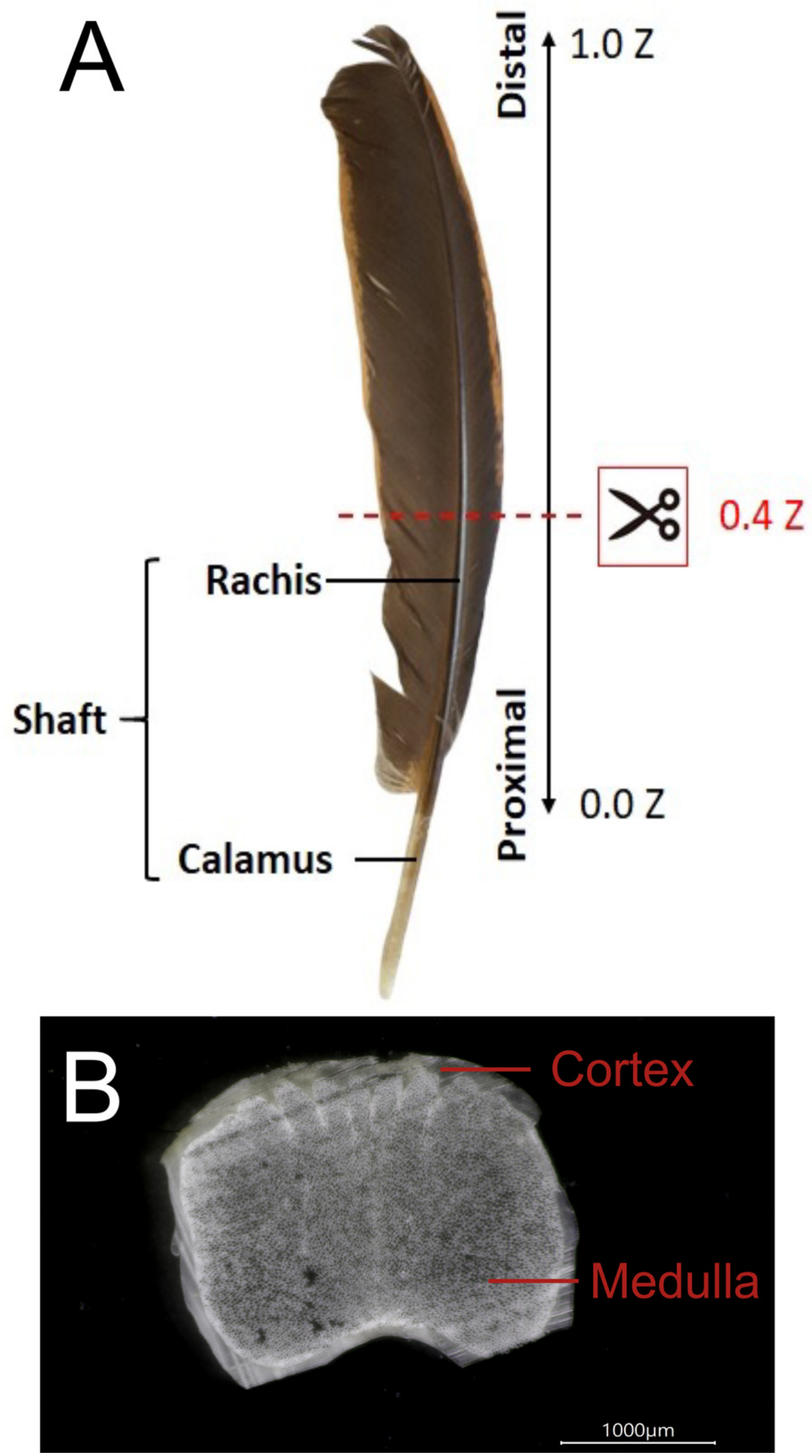

Peer] reviewing PDF | (2021:10:67226:1:1:NEW 14 Jan 2022) 
Figure 2

The representative SR-FTIR spectra of feather shaft medulla of different birds.

From top to bottom, they were domestic chickens, mallards, African sacred ibis, crested goshawks, collared owls, budgerigars, and zebra finches.

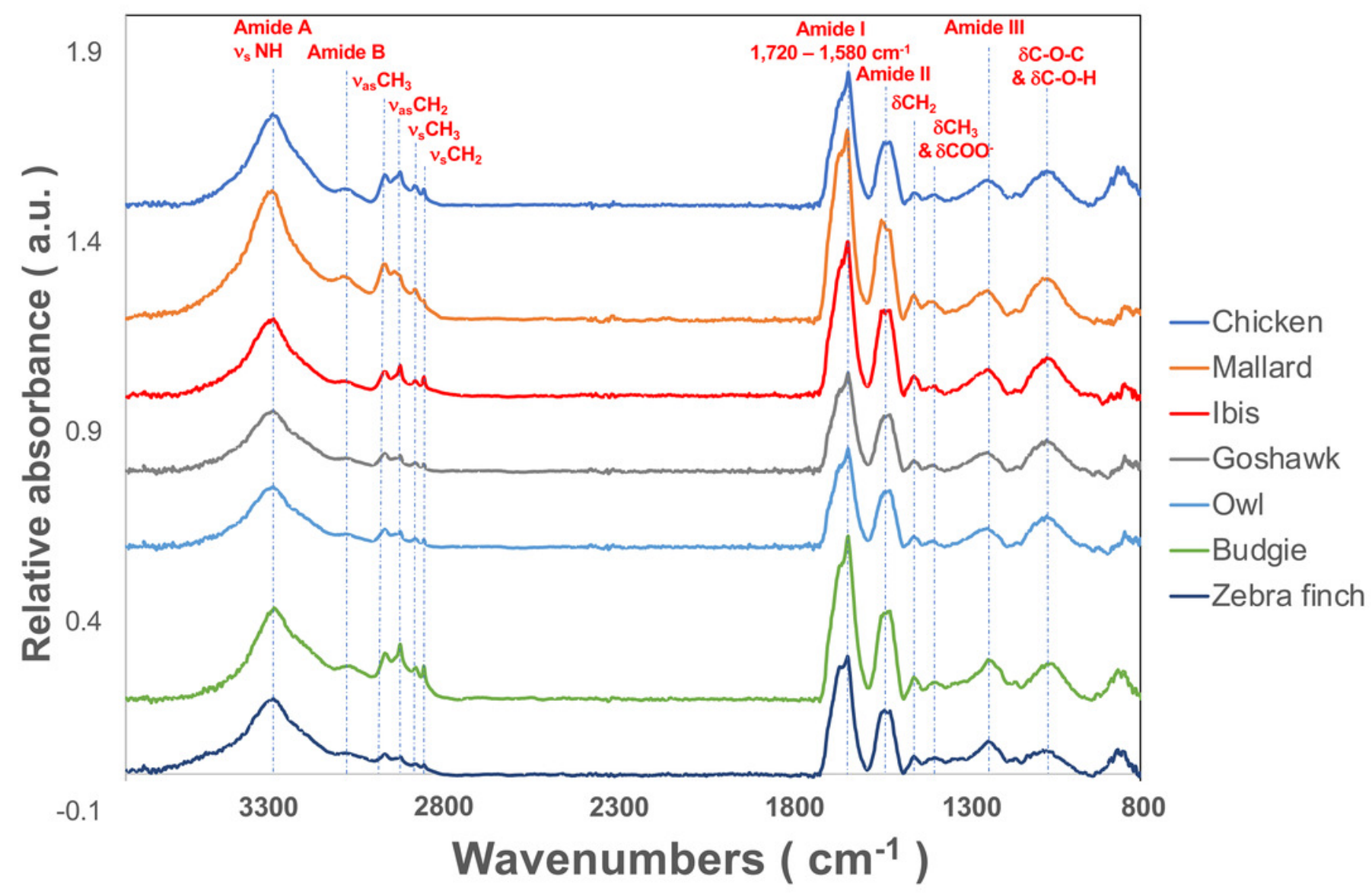


Figure 3

The spectral deconvolution of the Amide I band of the rachis medulla of domestic chicken flying feathers.

The representative spectral deconvolution of the eight resolved components spaned in the Am I absorption band. The black line was the calculated spectrum after the curve fitting process, and the red line is the normalized original Am I absorption band.

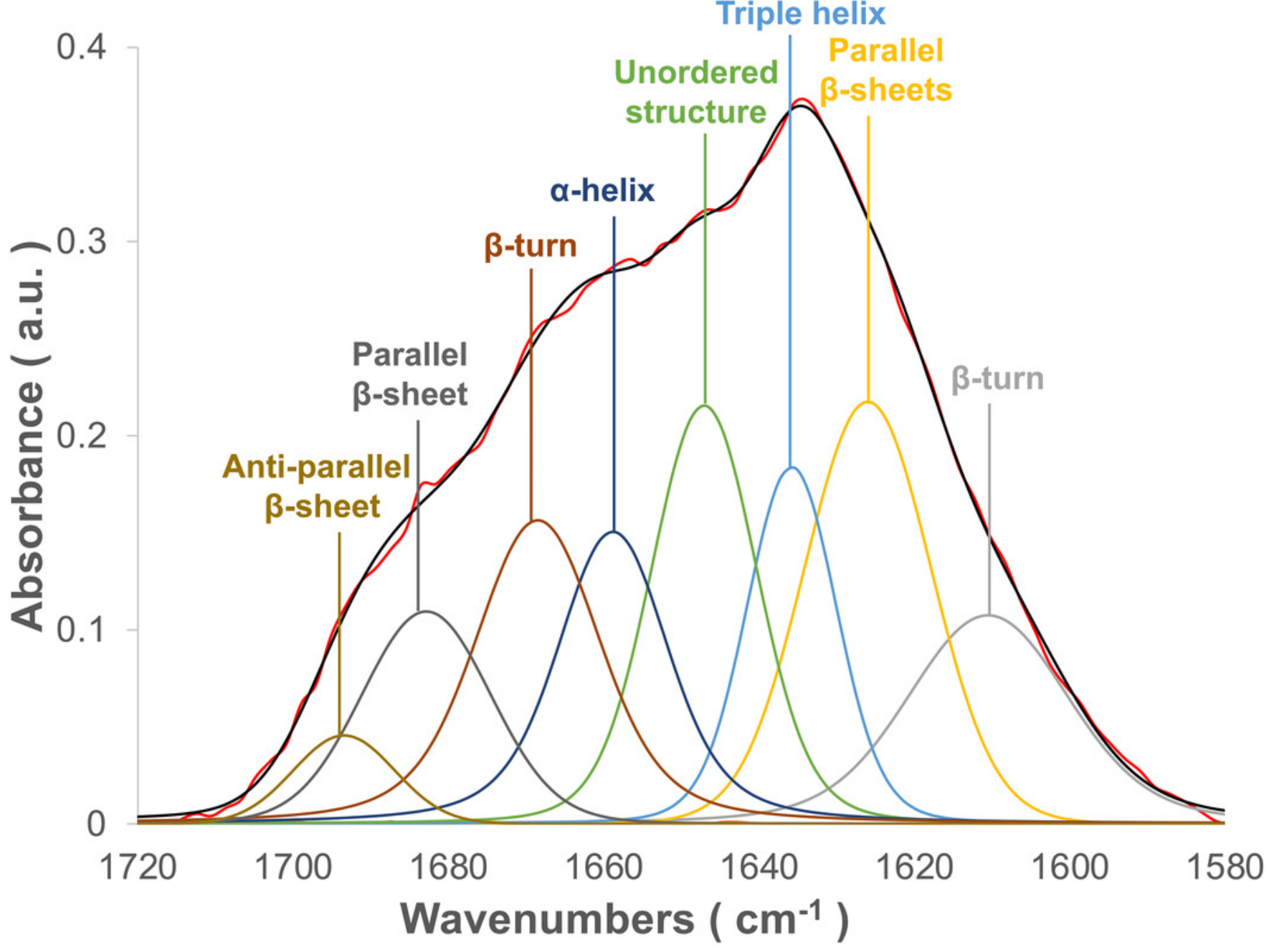


Figure 4

The ratio of the area under the curve of each PSS to the total area of Amide I band under the curve fitting of the Amide I absorption spectrum of the feather rachis cortex (A) and medulla (B).

From left to right on the horizontal axis are the absorption peaks of each secondary structure from low to high wavenumbers, and the vertical axis is the percentage of the area. 
A $30 \%$

$25 \%$

$20 \%$

$10 \%$

$5 \%$

$0 \%$

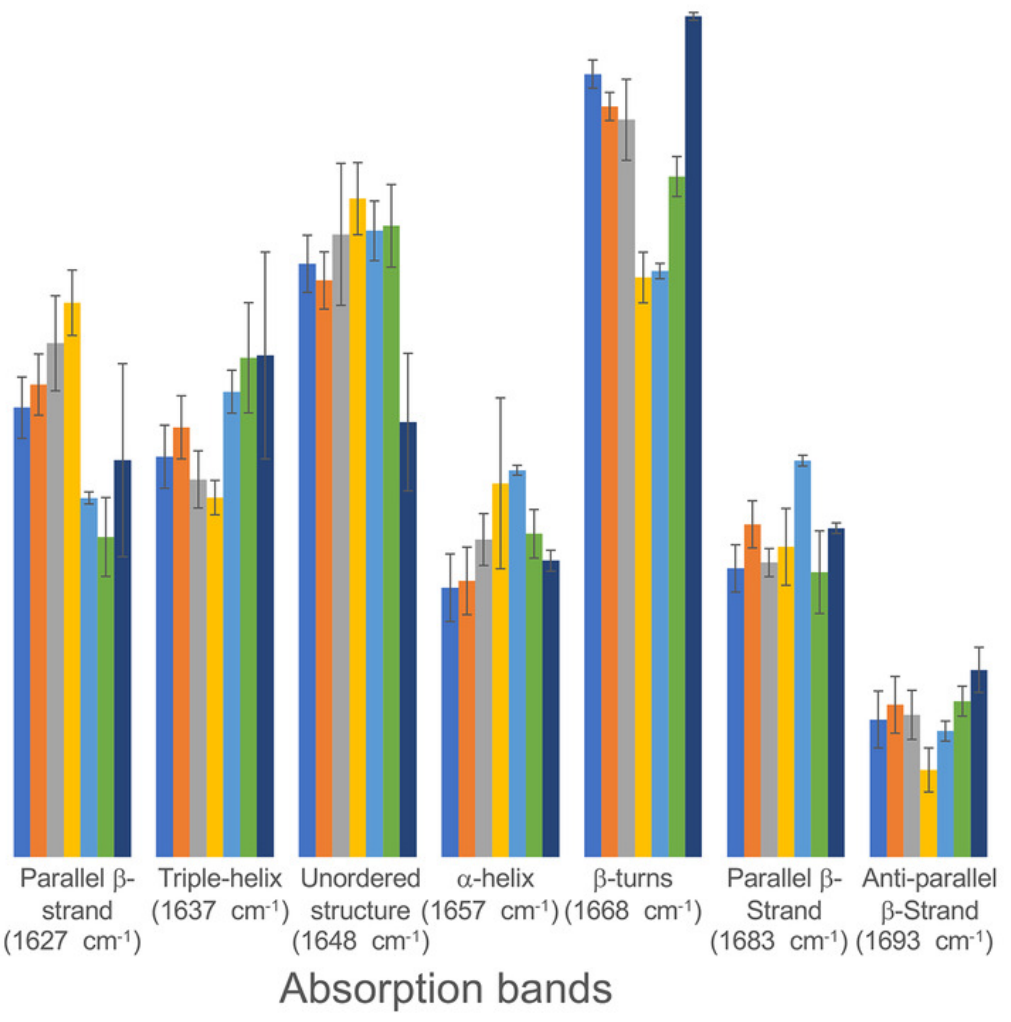

- Chicken

mallard

- Ibis

n Goshawk

- Owl

- Budgie

- Zebra finch

B $30 \%$

$25 \%$

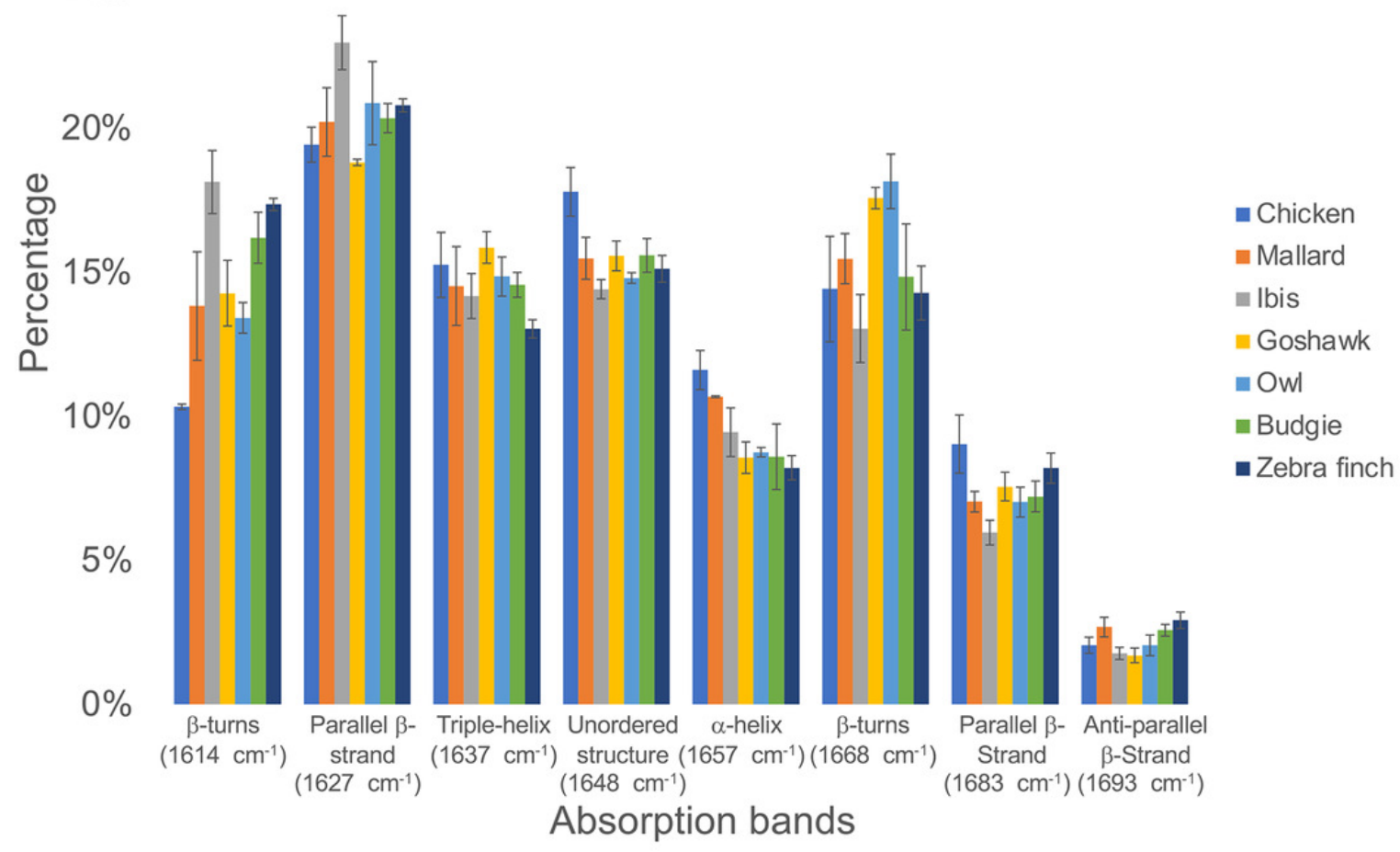




\section{Figure 5}

Representative spectral images of Am I band with SR-FTIRM for Feather shaft medulla of seven species of birds.

(A) The area of red grid boxes is the mapping area of the spectral image, and each red grid box $\left(10 \times 10 \mathrm{~mm}^{2}\right)$ of sampling point is the sub-area where the absorption spectrum was measured. (B) Spectral images of cross-section feather samples were constructed by integrating the peak height of the Amide I band. 


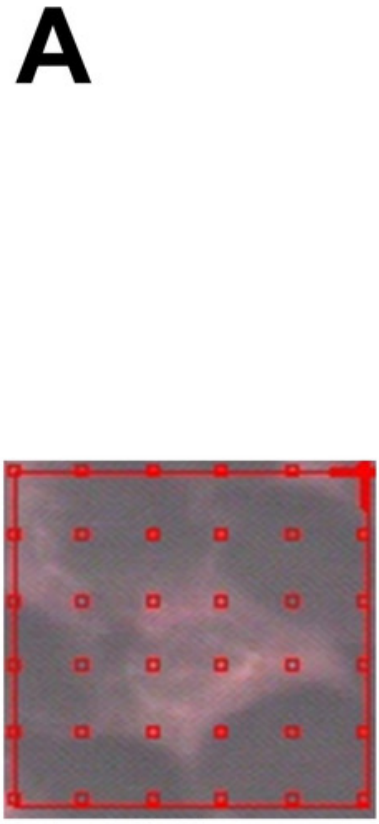

Goshawk ( 0.3Z )
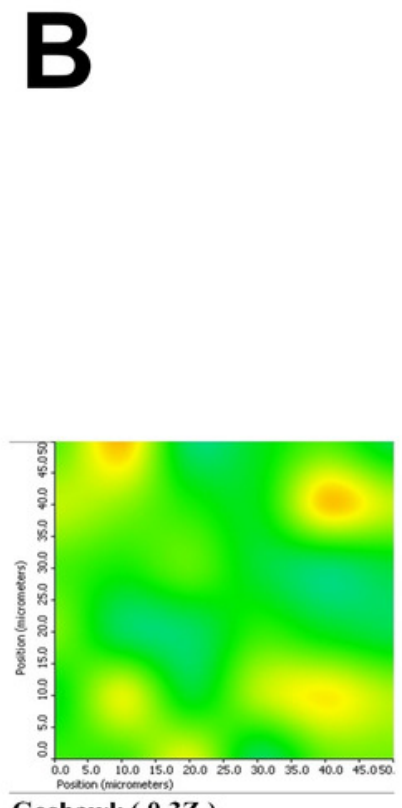

Goshawk ( 0.3Z)

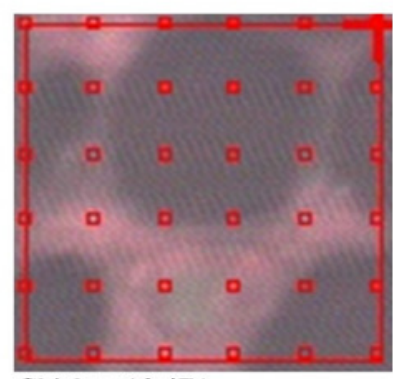

Chicken ( 0.4Z )

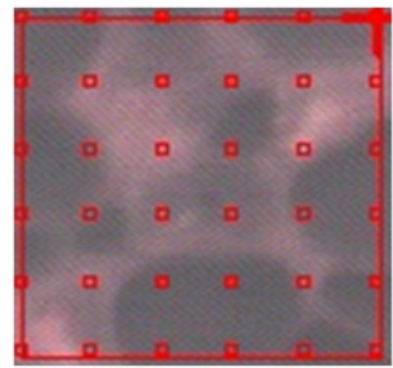

Owl ( 0.2Z)

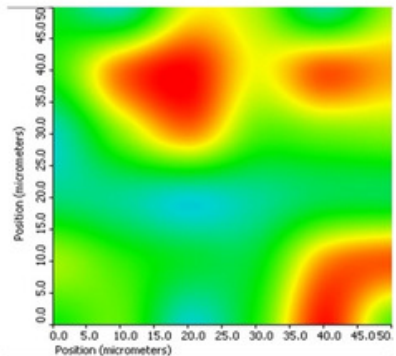

Chicken ( 0.4Z)

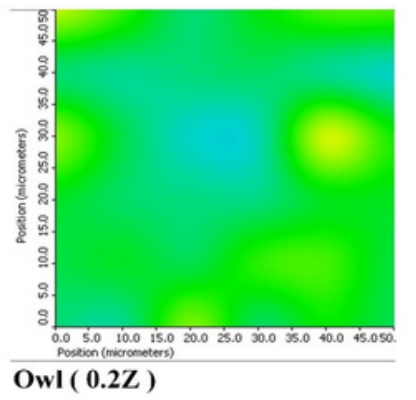

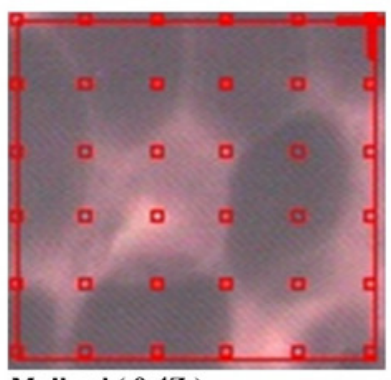

Mallard ( 0.4Z)

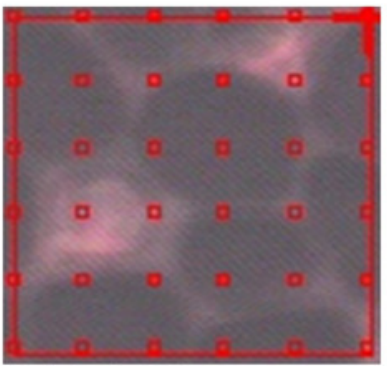

Budgie ( 0.4Z )

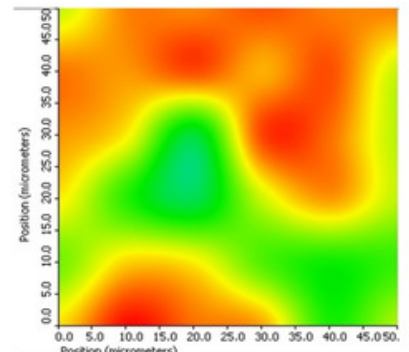

Mallard ( 0.4Z)

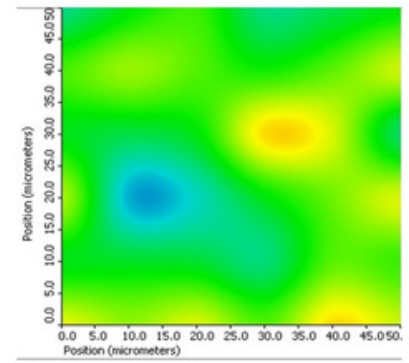

Budgie ( 0.4Z )

Intensity (a.u. )

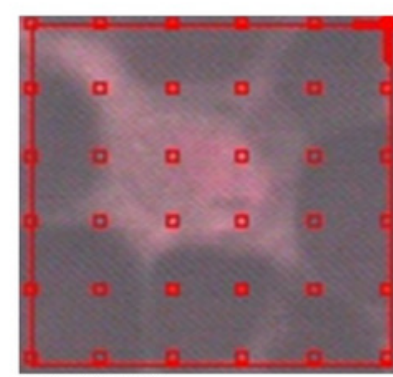

Ibis ( $0.5 Z)$

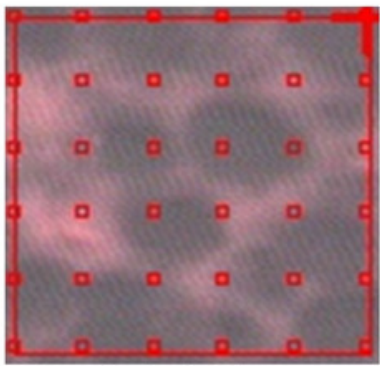

Zebra Finch ( 0.2Z)

$\overline{10 \mu \mathrm{m}}$

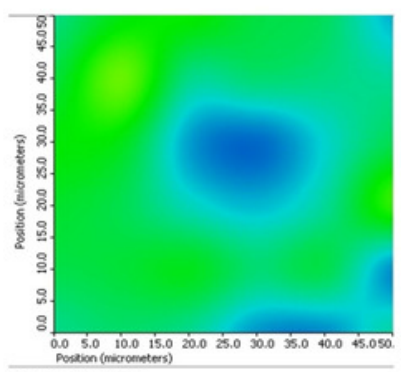

Ibis ( $0.5 Z$ )

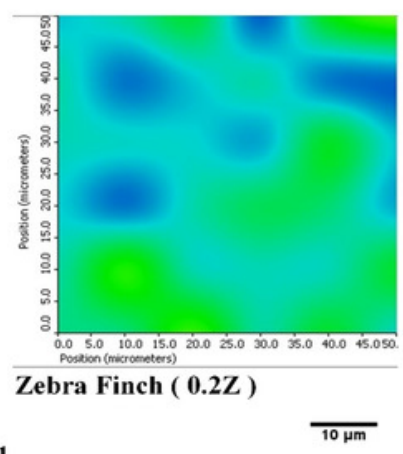

